\title{
EKSPERIMENTASI PEMBELAJARAN RME DENGAN PROBLEM SOL VING DAN RME DENGAN PROBLEM POSING DITINJAU DARI KREATIVITAS SISWA
}

\author{
Satrio Wicaksono Sudarman \\ FKIP Universitas Muhammadiyah Metro \\ E-mail : rio_sudarman@yahoo.com
}

\begin{abstract}
The aim of the research was to determine the effect of learning models on mathematics achievement viewed from the student creativity. The learning model compared were RME with problem solving, RME with problem posing on conventional. The type of the research was a quasi-experimental research. The population was the students of Junior High School in Surakarta city on academic year 2012/2013. The samples of this research were taken by using the stratified cluster random sampling technique. The samples consisted of 269 students who were divided into 90 students in the first experiment class, 90 students in the second experiment class, and 89 students in the control class. The result of research showed that: (1) RME with problem solving provided better learning achievement than RME with problem posing and the conventional model. The RME learning model with problem posing provided better learning achievement than conventional one, (2) the students having high creativity had better learning achievement than those having medium and low creativity. The students having medium creativity had better learning achievement than did those having low creativity, (3) students taught by using RME with problem solving having high creativity level had better learning achievement than those having medium and low creativity level and students having medium creativity level had learning achievement as good as the low creativity level. Students taught by using RME with problem posing and conventional model had equal learning achievement in each level of creativity, and (4) students having high creativity level taught by using RME with problem solving had better learning achievement than those taught by using RME with problem posing and conventional model. Students having high creativity taught by using RME with problem posing and conventional model had equally good learning achievement. Students having medium and low creativity level had equal learning achievement in each learning model.
\end{abstract}

Keywords: RME with problem solving, RME with problem posing, learning achievement, creativity

Aksioma 


\section{PENDAHULUAN}

Pesatnya perkembangan ilmu pengetahuan dan teknologi membawa pengaruh yang besar terhadap pola pikir masyarakat. Program pendidikan yang ada saat ini diharapkan mampu menyediakan sumber daya manusia untuk dapat menjawab dan memecahkan masalah yang sesuai dengan tuntutan zaman. Untuk memenuhi kebutuhan tersebut, dapat diwujudkan dalam bentuk pembaharuan dunia pendidikan serta penekananpenekanan pada hal-hal yang masih kurang diminati siswa. Inti dari pokok pendidikan untuk siswa adalah belajar, dalam arti pembelajaran dimulai dari masalah yang kompleks untuk dipecahkan, kemudian menghasilkan atau menemukan keterampilan yang dibutuhkan.

Matematika adalah salah satu pelajaran mendasar yang diajarkan di sekolah. Matematika merupakan ilmu pengetahuan yang sangat berguna untuk menyelesaikan permasalahan dalam kehidupan sehari-hari. Matematika juga merupakan dasar untuk memahami ilmu pengatahuan lainnya, seperti fisika dan kimia. Hal ini yang menyebabkan matematika dijadikan mata pelajaran wajib di setiap jenjang pendidikan formal. Peker (2008: 21) mengatakan bahwa rendahnya tingkat pemahaman matematika siswa telah mengkhawatirkan untuk waktu yang lamadi banyak negara. Banyak factor yang mempengaruhi proses pembelajaran matematika, diantaranya adalah ketakutan siswa pada matematika sehingga prestasi belajar siswa tidak sesuai dengan yang diharapkan.

Pemerintah, guru dan orang tua siswa selalu berupaya untuk meningkatkan prestasi belajar siswa. Usaha-usaha yang telah dilakukan belum menunjukkan hasil yang memuaskan khususnya untuk mata pelajaran matematika. Pada Ujian Nasional tingkat SMPN/MTs seKabupaten Surakarta, siswa yang lulus $71,62 \%$ dan siswa yang tidak lulus $28,38 \%$ untuk seluruh mata pelajaran. Mata pelajaran matematika pada siswa SMP Negeri 20 Surakarta tergolong paling rendah dari 43 SMPN/MTs yang ada di Kabupaten Surakarta.Hal ini berdasarkan data nilai tertinggi 8,76 , nilai terendah 4,88 dan nilai rata-rata 6,02. Pada Ujian Nasional tahun 2010/2011, nilai rata-rata untuk matematika berada dibawah nilai ratarata mata pelajaran yang lain. (Dinas Pendidikan Kabupaten Surakarta 2010/2011)

Untuk meningkatkan prestasi belajar matematika, banyak hal yang perlu diperhatikan. Salah satu hal yang perlu diperhatikan serius adalah proses pembelajaran matematika. Belajar matematika merupakan belajar konsep. Hal yang paling penting adalah bagaimana siswa dapat memahami konsep-konsep dasar dalam matematika. 
Dalam proses pembelajaran siswa diharapkan tidak hanya mendengarkan, mencatat dan menghafalkan materi maupun rumus-rumus yang diberikan guru, melainkan siswa dituntut aktif berperan dalam kegiatan pembelajaran, siswa harus mampu berfikir kritis dan berargumen dalam memecahkan berbagai persoalan dalam matematika.

Untuk mencapai tujuan tersebut diperlukan model pembelajaran yang tepat. Guru harus mempunyai kreativitas agar pembelajaran menjadi menarik dan siswa dapat belajar secara efektif. Oleh karena itu pemilihan model pembelajaran yang tepat sangat penting, karena tidak semua model pembelajaran dapat digunakan pada tiap pokok bahasan. Kebanyakan guru menggunakan model pembelajaran dengan pendekatatan mekanistik, yaitu pembelajaran langsung dengan metode ceramah dan ekspositori dalam menyajikan pelajaran. Metode ini cenderung terpusat pada guru, sehingga dominan guru akan mengakibatkan siswa kurang aktif dan kurang bisa berfikir kritis karena siswa menganggap semua yang disampaikan guru adalah benar dan harus diikuti.

Selain penggunaan model pembelajaran yang tepat, kreativitas selama proses pembelajaran juga perlu mendapat perhatian. Dalam pembelajaran, agar bermakna tidak cukup hanya dengan mendengar dan melihat tetapi harus imajinatif, mempunyai kepercayaan diri, mempunyai

ide-ide dalam menyelesaikan permasalahan matematika dalam kehidupan seharihari. Dalam perkembangan paradigma pembelajaran, guru masih sering merasa bingung dan kesulitan dalam menggunakan model pembelajaran yang akan digunakan. Setiap model pembelajaran yang dikembangkan selalu memiliki kelebihan, akan tetapi tidak semua model pembelajaran cocok digunakan dalam semua materi pelajaran. Kesulitan yang dialami siswa adalah mereka cenderung menghafal rumus dan contoh soal, sehingga apabila diberi soal yang berbeda dengan contoh soal, mereka akan kesulitan.

Menurut Marpaung (2001: 3), PMR dilandasi oleh pandangan bahwa siswa harus aktif, tidak boleh pasif. Siswa harus aktif mengkonstruksi sendiri pengetahuan matematika. Pembelajaran tidak dimulai dari definisi, teorema atau sifat-sifat kemudian dilanjutkan dengan contoh-contoh seperti yang selama ini dilaksanakan di berbagai sekolah. Sifat-sifat, definisi dan teorema itu diharapkan seolah-olah ditemukan kembali oleh siswa melalui penyelesaian masalah kontekstual yang diberikan guru di awal pembelajaran. Siswa didorong atau ditantang untuk aktif bekerja sehingga dapat mengkonstruksi atau membangun sendiri pengetahuan yang diperolehnya.

Penelitian ini mempunyai tujuan untuk mengetahui: (1) di antara model pembelajaran yang memberikan 
prestasi belajar matematika lebih baik, model pembelajaran $R M E$ dengan problem solving, $R M E$ dengan problem posing dan pembelajaran konvensional, (2) manakah di antara kategori kreativitas siswa yang dapat memberikan prestasi belajar matematika lebih baik, apakah kategori kreativitas tinggi, sedang atau rendah, (3) manakah yang memberikan prestasi belajar matematika lebih baik, model pembelajaran $R M E$ dengan problem solving, model pembelajaran $R M E$ dengan problem posing atau pembelajaran konvensional pada masing-masing tingkat kategori kreativitas siswa, (4) pada masingmasing tingkat kreativitas siswa, manakah yang memberikan prestasi belajar matematika lebih baik pada model pembelajaran $R M E$ dengan problem solving, model pembelajaran RME dengan problem posingatau pembelajaran konvensional.

\section{METODE PENELITIAN}

Penelitian ini dilaksanakan di SMP Negeri SeKota Surakarta pada semester ganjil tahun pelajaran 2012/2013. Jenis penelitian adalah penelitian eksperimental semu (quasi experimental research). Populasi dalam penelitian ini adalah siswa SMP Kelas VIII semester ganjil tahun pelajaran 2012/2013. Sampling yang digunakan dalam penelitian adalah teknik stratified cluster random sampling sehingga terpilih sampel sebagai kelompok tinggi yaitu siswa SMP Negeri 8 Surakarta,kelompok sedang yaitu siswa SMP Negeri 5 Surakarta, dan kelompok rendah yaitu siswa SMP Negeri 16 Surakarta.

Metode pengumpulan data penelitian meliputi metode dokumentasi, tes, dan angket. Sebelum melakukan eksperimen, dilakukan uji keseimbangan terhadap kemampuan awal matematika menggunakan anava satu jalan dengan sel tak sama. Data prestasi belajar matematika dianalisis menggunakan analisis variansi dua jalan dengan sel tak sama. Uji hipotesis menggunakan analisis variansi dua jalan dengan sel taksama. Apabilahasil analisis variansi menunjukkan bahwa hipotesis nol ditolak, dilakukan uji komparasi ganda menggunakan metode Scheffe'. (Budiyono, 2009: 170-216).

\section{HASIL PENELITIAN DAN PEMBAHASAN}

Hasil uji prasyarat menyimpulkan bahwa semua sampel berasal dari populasi yang berdistribusi normal dan populasi-populasi yang mempunyai variansi yang sama. Hasil uji keseimbangan diperoleh simpulan bahwa populasi mempunyai kemampuan awal yang seimbang. Deskripsi data hasil penelitian di sajikan pada Tabel 1 berikut: 
Tabel 1. Deskripsi Data Prestasi Belajar Matematika Siswa

\begin{tabular}{|c|c|c|c|c|}
\hline \hline \multirow{2}{*}{ Model } & Tinggi & Sedang & Rendah \\
\hline \multirow{3}{*}{$\begin{array}{c}\text { RME dengan } \\
\text { Problem Solving }\end{array}$} & & & \\
\cline { 2 - 5 } & Nilai Min & 76 & 40 & 44 \\
\cline { 2 - 5 } & Nilai maks & 100 & 96 & 96 \\
\cline { 2 - 5 } & & $\mathbf{9 2 , 1 4}$ & $\mathbf{6 9 , 9 3}$ & $\mathbf{6 7 , 1 3}$ \\
\cline { 2 - 5 } & & 16,67 & 13,55 & 15,16 \\
\hline \multirow{4}{*}{$\begin{array}{c}\text { PME dengan } \\
\text { Problem Posing }\end{array}$} & & 29 & 30 & 31 \\
\cline { 2 - 5 } & Nilai Min & 36 & 48 & 36 \\
\cline { 2 - 5 } & Nilai maks & 92 & 88 & 84 \\
\cline { 2 - 5 } & & $\mathbf{7 0 , 0 7}$ & $\mathbf{6 7 , 6 0}$ & $\mathbf{5 7 , 5 5}$ \\
\cline { 2 - 5 } & & 15,88 & 12,44 & 12,64 \\
\hline Konvensional & & 21 & 37 & 32 \\
\cline { 2 - 5 } & Nilai Min & 40 & 32 & 32 \\
\cline { 2 - 5 } & Nilai maks & 96 & 96 & 88 \\
\cline { 2 - 5 } & & $\mathbf{6 3 , 2 4}$ & $\mathbf{5 4 , 8 1}$ & $\mathbf{5 5 , 1 3}$ \\
\cline { 2 - 5 } & & 20,44 & 14,51 & 16,81 \\
\hline
\end{tabular}

Dengan taraf signifikansi 0,05, variansi dua jalan dengan sel tak rangkuman hasil perhitungan analisis. sama disajikan dalam Tabel 2 berikut

Tabel 2. Rangkuman Analisis Variansi Dua Jalan dengan Sel Tak Sama Sumber Keputusan Uji

\begin{tabular}{|l|c|c|c|c|c|c|}
\hline \multicolumn{1}{|c|}{ Sumber } & $J K$ & $d k$ & $R K$ & $F_{\text {obs }}$ & $F_{\alpha}$ & Keputusan Uji \\
\hline Model $(A)$ & 15547,1339 & 2 & 7773,5669 & 35,7099 & 3,00 & Ho ditolak \\
\hline Kreativitas $(B)$ & 10856,7258 & 2 & 5428,3629 & 24,9366 & 3,00 & Ho ditolak \\
\hline Interaksi $(A B)$ & 4054,2887 & 4 & 1013,5722 & 4,6561 & 2,37 & Ho ditolak \\
\hline Galat $(G)$ & 56598,52 & 260 & 217,6866 & & - & \\
\hline \multicolumn{1}{|c|}{ Total } & 87056,6637 & 68 & - & - & - & \\
\hline
\end{tabular}

Berdasarkan tabel di atas, $H_{0 A} \quad R M E$ dengan problem solving, $R M E$ ditolak berarti model pembelajaran dengan problem posing, dan 
konvensional memberikan efek yang berbeda terhadap prestasi pembelajaran. Hipotesis $H_{O B}$ ditolak berarti kategori kreativitastinggi, sedang, dan rendah memberikan efek yang berbeda terhadap belajar prestasi pembelajaran. Hipotesis $H_{0 A B}$ ditolak berarti terdapat interaksi antara model pembelajaran dan kategori kreativitas siswa terhadap prestasi pembelajaran.

Untuk hipotesis $H_{0}$ ditolak dilakukan uji komparasi ganda. Oleh karena $H_{0 A}$ ditolak, perlu dilakukan uji komparasi rerata antar baris.

Tabel 3. Rangkuman Hasil Uji Komparasi Rerata Antar Baris Pada Masing-Masing Model Pembelajaran

\begin{tabular}{|c|c|c|c|}
\hline$H_{0}$ & $F_{\text {hit }}$ & $F_{\text {tabel }}$ & Keputusan Uji \\
\hline$\mu_{1 .}=\mu_{2 .}$ & 24,7684 & 6,00 & $H_{0}$ ditolak \\
\hline$\mu_{1 .}=\mu_{3 .}$ & 74,3746 & 6,00 & $H_{0}$ ditolak \\
\hline$\mu_{2 .}=\mu_{3 .}$ & 3,3774 & 6,00 & $H_{0}$ diterima \\
\hline
\end{tabular}

Hasil uji komparasi ganda menunjukkan bahwa prestasi belajar matematika siswa yang dikenai model pembelajaran $R M E$ dengan problem solving lebih baik daripada $R M E$ dengan problem posing dan konvensional. Hal ini disebabkan pada pembelajaran $R M E$ dengan problem posing belum menekankan agar siswa dapat menguasai materi yang diajarkan, melainkan lebih menekankan pada pemahaman mereka. Siswa masih kesulitan dalam membuat pertanyaan. Pembelajaran RME dengan problem solving terdapat kegiatan siswa yang diharuskan dalam memecahkan permasalahan baik secara individu maupun kelompok. Berbeda halnya
RME dengan problem posing dan konvensional yang proses pembelajarannya hanya sedikit waktu yang digunakan dalam memecahkan masalah. Hasil dari pengamatan di lapangan dimungkinkan kurang siapnya siswa dengan pembelajaran $R M E$ dengan problem posing dan konvensional. Siswa kadang masih bingung terhadap soal yang akan dibuat. Prestasi belajar matematika siswa yang dikenai pembelajaran $R M E$ dengan problem posing dan pembelajaran konvensional sama baiknya.

Oleh karena $H_{0 B}$ ditolak, perlu dilakukan uji komparasi rerata antar kolom.

Tabel 4. Rangkuman Hasil Komparasi Antar Kolom

\begin{tabular}{|l|l|l|l|}
\hline$H_{0}$ & $F_{\text {hit }}$ & $F_{\text {tabel }}$ & Keputusan Uji \\
\hline
\end{tabular}




\begin{tabular}{|c|c|c|c|}
\hline$\mu_{\cdot 1}=\mu_{\cdot 2}$ & 32,2826 & 6,00 & $H_{0}$ ditolak \\
\hline$\mu_{\cdot 1}=\mu_{\cdot 3}$ & 51,6123 & 6,00 & $H_{0}$ ditolak \\
\hline$\mu_{\cdot 2}=\mu_{\cdot 3}$ & 2,5612 & 6,00 & $H_{0}$ diterima \\
\hline
\end{tabular}

$H_{0 B}$ ditolak berarti dilakukan uji komparasi antar kolom. Hasil pengujian hipotesis menunjukkan bahwa prestasi belajar matematika siswa yang memiliki kreativitas tinggi lebih baik dibandingkan siswa yang memiliki kreativitas sedang dan rendah, dan prestasi belajar matematika siswa yang memiliki kreativitas sedang lebih baik dibandingkan siswa yang memiliki kreativitas rendah.Hasil penelitian ini sesuai dengan hipotesis penelitian yang menunjukkan bahwa prestasi belajar matematika siswa berbanding lurus dengan kreativitas siswa. Semakin tinggi kreativitas siswa,semakin baik pula prestasi belajar yang diperolehnya. Hai ini disebabkan karena dengan semakin tinggi kreativitas yang dimiliki siswa, maka memiliki berbagai macam kreativitas yang banyak terhadap sejumlah konsep tentang sistem persamaan linear dua variabel. Lee dan Bharath (2010) bahwa siswa yang memiliki kreativitas tinggi dapat mengkontruksi pengetahuan sehingga dapat menyelesaikan permasalahan dalam kehidupan nyata. Siswa juga memiliki kemampuan untuk berfikir yang baru dan berbeda.

Berdasarkan hasil angket kreativitas, siswa yang memiliki kreativitas tinggi memiliki kebiasaan dalam mencari berbagai referensi dari konsep maupun permasalahan dalam pembelajaran, bertanya pada guru matematika tentang kesulitan yang dialami, aktif mengikuti diskusi dengan teman dalam mengerjakan tugas matematika, dalam mempelajari materi matematika siswa tidak hanya menghapal namun memahaminya sehingga apabila diberikan permasalahan yang berbeda siswa dapat menyelesaikannya. Dengan demikian, semakin tinggi kreativitas, maka pemahaman siswa semakin optimal sehingga memperoleh prestasi belajar matematika yang optimal pula. Hasil ini sesuai dengan simpulan Riawan Yudi Purwoko (2011) bahwa prestasi belajar matematika siswa yang memiliki kreativitas tinggi lebih baik dibandingkan prestasi belajar matematika siswa yang memiliki kreativitas sedang dan rendah. Prestasi belajar matematika siswa yang memiliki kreativitas sedang sama baiknya dengan siswa yang memiliki kreativitas rendah.

Oleh karena $H_{0 A B}$ ditolak, perlu dilakukan uji komparasi rerata antar sel pada masing-masing kategori model pembelajaran dan kreativitas. 
Tabel 5. Rangkuman Hasil Komparasi Antar Sel pada Baris yang Sama

\begin{tabular}{|c|c|c|c|}
\hline$H_{0}$ & $F_{h i t}$ & $F_{\text {tabel }}$ & Keputusan Uji \\
\hline$\mu_{11} v s \mu_{12}$ & 32,2863 & 15,52 & $H_{0}$ ditolak \\
$\mu_{11} v s \mu_{13}$ & 42,9364 & 15,52 & $H_{0}$ ditolak \\
$\mu_{12} v s \mu_{13}$ & 0,5503 & 15,52 & $H_{0}$ diterima \\
\hline$\mu_{21} v s \mu_{22}$ & 0,4129 & 15,52 & $H_{0}$ diterima \\
$\mu_{21} v s \mu_{23}$ & 10,7901 & 15,52 & $H_{0}$ diterima \\
$\mu_{22} v s \mu_{23}$ & 7,0761 & 15,52 & $H_{0}$ diterima \\
\hline$\mu_{31} v s \mu_{32}$ & 4,3706 & 15,52 & $H_{0}$ diterima \\
$\mu_{31} v s \mu_{33}$ & 3,8338 & 15,52 & $H_{0}$ diterima \\
$\mu_{32} v s \mu_{33}$ & 0,0078 & 15,52 & $H_{0}$ diterima \\
\hline
\end{tabular}

a. Pada siswa yang dikenai model pembelajaran $R M E$ dengan problem solving, prestasi belajar matematika siswa yang memiliki kreativitas tinggi lebih baik dibandingkan prestasi belajar matematika siswa yang memiliki kreativitas sedang maupun rendah. Prestasi belajar matematika siswa yang memiliki kreativitas sedang sama baiknya dengansiswa yang memiliki kreativitas rendah. Hal ini dimungkinkan karena pembentukan kelompok belajar pada pembelajaran $R M E$ dengan problem solving tidak memperhatikan heterogenitas kreativitas siswa. Dalam melaksanakan penelitian, data kreativitas siswa diukur pada pertemuan terakhir untuk pembelajaran ini. Dengan demikian, peneliti tidak mampu menjamin terjadinya interaksi belajar antara siswa yang memiliki kreativitas tinggi, sedang dan rendah. Hal ini sesuai dengan penelitian Ozdemir dan Uzel (2011) bahawa pembelajaran matematika realistik dapat meningkatkan prestasi belajar siswa dengan problem solving. Siswa dapat menginterpretasi suatu proses dalam menemukan suatu konsep dan mengembangkan kemampuannya dalam memecahkan masalah. Pembelajaran realistik memberikan suasana yang nyaman dan melibatkan aktivitas setiap siswa dalam kelompok.

b. Pada siswa yang dikenai model pembelajaran $R M E$ dengan problem posing dan konvensional, prestasi belajar matematika sama baiknya 
pada masing-masing kreativitas. Hal ini dimungkinkan karena penerapan model pembelajaran $R M E$ dengan problem posing ini mampu mengakomodasi seluruh siswa dengan kreativitas yang berbedabeda dalam suatu kelompok untuk berdiskusi dalam menyelesaikan masalah. Pada pembelajaran konvensional hal ini dimungkinkan karena kreativitas siswa tidak terlihat dimana pembelajarannya berpusat pada guru. Dalam pelaksanaan penelitian, data kreativitas siswa diukur pada pertemuan terakhir.

Berdasarkan hasil komparasi rerata antar sel pada kolom yang sama pada masing-masing kategori model pembelajaran dan kreativitas, diperoleh simpulan bahwa:

Tabel 6. Rangkuman Hasil Komparasi Antar Sel pada Kolom yang Sama

\begin{tabular}{|c|c|c|c|}
\hline$H_{0}$ & $F_{\text {hit }}$ & $F_{\text {tabel }}$ & Keputusan Uji \\
\hline$\mu_{11} v s \mu_{21}$ & 31,8865 & 15,52 & $H_{0}$ ditolak \\
$\mu_{21} v s \mu_{31}$ & 2,6108 & 15,52 & $H_{0}$ diterima \\
$\mu_{11} v s \mu_{31}$ & 46,0562 & 15,52 & $H_{0}$ ditolak \\
\hline$\mu_{12} v s \mu_{22}$ & 0,3681 & 15,52 & $H_{0}$ diterima \\
$\mu_{22} v s \mu_{32}$ & 2,4481 & 15,52 & $H_{0}$ diterima \\
$\mu_{12} v s \mu_{32}$ & 7,0742 & 15,52 & $H_{0}$ diterima \\
\hline$\mu_{13} v s \mu_{23}$ & 6,6338 & 15,52 & $H_{0}$ diterima \\
$\mu_{23} v s \mu_{33}$ & 0,4248 & 15,52 & $H_{0}$ diterima \\
$\mu_{13} v s \mu_{33}$ & 10,5840 & 15,52 & $H_{0}$ diterima \\
\hline
\end{tabular}

a. Pada siswa yang memiliki kreativitas tinggi, prestasi belajar siswa yang dikenai model pembelajaran $R M E$ dengan problem solving lebih baik dari model pembelajaran $R M E$ dengan problem posing dan konvensional. Sedangkan prestasi belajar matematika siswa yang dikenai model pembelajaran $R M E$ dengan problem posing sama baiknya dengan pembelajaran konvensional. Hal ini tidak sesuai dengan hipotesis penelitian karena dalam pengisian angket kreativitas masih banyak siswa pada kelompok kontrol yang kurang jujur yang berpengaruh pada pembagian 
kelompok siswa berdasarkan tingkat kreativitas siswa untuk kategori tinggi, sedang dan rendah. Hal ini sesuai dengan simpulan Font dan Malaspina (2010) bahwa pembelajaran model problem solving dengan dikaitkan pada permasalahan dalam kehidupan sehari-hari dapat mengoptimalkan prestasi belajar siswa.

b. Pada siswa yang memiliki kreativitas sedang dan rendah, prestasi belajar matematika siswa yang dikenai model pembelajaran $R M E$ dengan problem solving, RME dengan problem posing dan konvensional sama baiknya. Hal ini berbeda dengan hipotesis penelitian dikarenakan pada kreativitas sedang dan rendah, pada saat proses pembelajaran membutuhkan bimbingan yang lebih untuk dapat mengikuti proses pembelajaran akan tetapi proses pembimbingan tidak berjalan maksimal karena keterbatasan waktu. Hasil ini sesuai dengan simpulan Nurmaningsih (2012) bahwa pada siswa yang mempunyai kategori kreativitas sedang dan rendah, untuk masingmasing model pembelajaran yaitu problem solving dan problem posing mempunyai prestasi belajar yang sama baiknya.

\section{KESIMPULAN DAN SARAN}

Berdasarkan analisis data dan pembahasan, maka dapat disimpulkan sebagai berikut:

1. Model RME dengan problem solving menghasilkan prestasi belajar matematika yang lebih baik dibandingkan dengan model $R M E$ dengan problem posing dan pembelajaran konvensional. Model RME dengan problem posing menghasilkan prestasi belajar matematika yang sama baiknya dengan pembelajaran konvensional.

2. Siswa dengan kategori kreativitas tinggi mempunyai prestasi belajar matematika yang lebih baik dibandingkan siswa dengan kategori kreativitas sedang dan rendah. Siswa dengan kategori kreativitas sedang mempunyai prestasi belajar matematika yang lebih baik dari kategori kreativitas rendah.

3. Siswa yang dikenai model $R M E$ dengan problem solving, kategori kreativitas tinggi mempunyai prestasi belajar matematika yang lebih baik dibandingkan dengan sedang dan rendah dan siswa yang mempunyai kategori kreativitas sedang, prestasi belajar matematika sama baiknya dengan kategori kreativitas rendah. Siswa yang dikenai model $R M E$ dengan problem posing dan pembelajaran konvensional, prestasi belajar matematika sama baiknya untuk masing-masing kategori kreativitas. 
4. Siswa yang mempunyai kategori kreativitastinggi, model $R M E$ dengan problem solving lebih baik dari model $R M E$ dengan problem posing dan model pembelajaran konvensional dan model $R M E$ dengan problem posing menghasilkan prestasi belajar matematika yang sama baiknya dengan pembelajaran konvensional. Siswa yang mempunyai kreativitas sedang dan rendah, prestasi belajar sama baiknya untuk masingmasing kategori model pembelajaran.

Dari kesimpulan di atas, diharapkan bagi guru dapat memilih model yang tepat dalam pembelajaran. Diantaranya model pembelajaran $R M E$ dengan problem solving pada siswa dengan kreativitas tinggi sehingga siswa dapat memecahkan masalah dalam kehidupan. Mengetahui model $R M E$ dengan problem posing dan konvensional pada kreativitas sedang dan rendah dalam penerapannya dalam pembelajaran. Bagi peneliti lain dapat digunakan sebagai acuan atau dapat dipakai sebagai salah satu referensi untuk melakukan penelitian yang lain.

\section{DAFTAR PUSTAKA}

Budiyono. 2009. Statistika Dasar untuk Penelitian Edisi ke-2. Surakarta: UNS Press.

Font, V. \& Malaspina, U. 2010. The role of intuition in the solving of optimization problems.

Netherlands Journal of

Education Study Mathematics. 27

(2): 107-130. Diunduh dari http://www.ejmste.com pada 24 Februari 2013 pukul 08.00 WIB.

Marpaung. 2001. Makalah Penyajian Bahan Ajar dan Contoh PMRI. Disajikan pada seminar di puskur Depdiknas 19 Agustus 2003.

Lee, K. H. dan Bharath, S. 2010. Conjecturing via reconceived classical analogy. Columbia. Journal of Educational Studies in Mathematics.76 (2): 123-140. Diunduh dari http://www.springerlink.com/con tent pada 17 Februari 2012 pukul $22.00 \mathrm{WIB}$.

Nurmaningsih. 2012. Eksperimentasi Model Pembelajaran Problem Solving dan Problem Posing Berbantuan Alat Peraga pada Materi Persamaan Garis Lurus Ditinjau dari Kreativitas Belajar Siswa SMP se-Kota Pontianak. Tesis S2. Tidak dipublikasikan. Program Pascasarjana UNS. Surakarta.

Ozdemir, U. \& Uzel, D. 2011. The effect of realistic mathematics education on student achievemented student opinions towards instruction. Journal of Education, 40: 332-343. Diunduh darihttp://www.ejmste.com pada 23 Februari 2013 pukul 07.00 WIB.

Peker, M. 2008. Pre-service elementary school teachers 'learning styles and attitude towards mathematics. 
ISSN 2442-5419 Vol. 3, No. 2 (2014) 23-34

Eurasia Journal of Mathematics, Science \& Technology Education, 4 (1): 21-26. Diunduh dari http://www.ejmste.com pada 22 Desember 2012 pukul 13.00 WIB.

Riawan Yudi Purwoko. 2011. Eksperimentasi Pembelajaran Matematika Realistik dengan Metode Peneluam Ditinjau dari Kreativitas Belajar Matematika Siswa. Tesis S2. Tidak dipublikasikan. Program Pascasarjana UNS. Surakarta. 